\title{
The use of HPV-DNA testing combined with Pap smear in detection of pre-invasive disease of the cervix
}

\author{
Fayrouz A. Nwesar ${ }^{1 *}$, Tawfik Abdel Salam T. ${ }^{1}$, Marwa Hanafi M. ${ }^{2}$, Layla K. Younis ${ }^{3}$, \\ Ziad S. Abou-Zeid ${ }^{1}$, Dalal M. N. Elkaffash ${ }^{2}$
}

${ }^{1}$ Department of Obstetrics and Gynecology, ${ }^{2}$ Department of Clinical and Chemical Pathology, ${ }^{3}$ Department of Pathology, Faculty of Medicine, Alexandria University, Egypt

Received: 28 September 2017

Accepted: 30 October 2017

\section{*Correspondence:}

Dr. Fayrouz A. Nwesar,

E-mail: drfayrouznwesar@yahoo.com

Copyright: () the author(s), publisher and licensee Medip Academy. This is an open-access article distributed under the terms of the Creative Commons Attribution Non-Commercial License, which permits unrestricted non-commercial use, distribution, and reproduction in any medium, provided the original work is properly cited.

\begin{abstract}
Background: Cancer cervix constitutes a major health problem worldwide. It is one of the most common female malignancy in both incidence and mortality. Cancer cervix has many risk factors, the most important one is persistent infection with one of HPV high risk types. Its morbidity and mortality can be reduced by frequent screening and early diagnosis. So that, several studies have been conducted in recent years in order to find better tests for screening for pre-invasive disease of the cervix and so early intervention and better prognosis. This study aimed to compare the sensitivity of Pap test and HPV DNA test as screening tests for pre-invasive disease of the cervix.

Methods: 100 females from those attending Alexandria University gynaecologic clinic for causes rather than cancer cervix were subjected to Pap smear and cervical swab for HPV-DNA testing at the same setting. Cases of HSIL or positive HPV were subjected to VIA test, colposcopy and cervical punch biopsy was taken if aceto-whitening of the cervix or any other abnormality was found. Cases with ASCUS or LSIL were re-smeared after 3-6 months, if persistent or progressive pathology, colposcopy and punch biopsy from acetowhite areas were taken.

Results: 21 cases $(21 \%)$ were HPV positive and 66 cases $(66 \%)$ were positive for intraepithelial lesions $(37 \%$ ASCUS, $18 \%$ LSIL and 11\% HSIL) with re-smearing there were 3 persistent ASCUS cases (8.1\%) and 5 LSIL cases (27.78\%). Colposcopy done, and biopsies were taken from 10 HSIL cases (90.1\%), 5 LSIL (27.8\%), 3 ASCUS (8.1\%) and $10 \mathrm{HPV}$ positive cases $(62.5 \%)$. With significant relationship between colposcopic findings and HPVDNA positivity and abnormal cytology. Biopsies were 18 ; 14 were CIN I and 4 were CIN II.

Conclusions: HPV-DNA positivity has positive association with HSIL. Pap smear is an easy cheap method for screening. HPV-DNA test is less sensitive than cytology as a method for screening.
\end{abstract}

Keywords: Cancer cervix, HPV-DNA, Papanicolaou smear, Pre-invasive disease of the cervix, Screening of cancer cervix

\section{INTRODUCTION}

Cancer cervix constitutes a major health problem worldwide. ${ }^{1}$ It is now the fourth most common female malignancy in both incidence and mortality. ${ }^{2}$ About $80 \%$ of cases in developing countries and about $87 \%$ of cervical cancer deaths occur in less developed regions. ${ }^{3}$
According to Egyptian cancer registry the incidence rate of cervical cancer/100.000 population in is $1.26 \%$, $1.06 \%, 0.48 \%$ in lower, middle and upper Egypt respectively. ${ }^{4}$

Risk factors for pre-invasive and invasive disease of the cervix include: human papilloma virus (HPV), multiple 
sexual partners and early sexual activity, high Parity, long term use of contraceptives, smoking, immunosuppression and low socioeconomic status. ${ }^{5,6}$ Among all known types of cancer, cervical cancer has some of the best chance for prevention and cure when diagnosed early, in the preinvasive stage. ${ }^{7}$

Screening for cervical cancer has been implemented in many countries, starting in the 1960 s and led to reduction in cervical cancer burden. ${ }^{8}$ The optimal screening strategy should identify those cervical cancer precursors likely to progress to invasive cancers (maximizing the benefits of screening) and avoid the detection and unnecessary treatment of transient HPV infection and its associated benign lesions that are not destined to become cancerous (minimizing the potential harms associated with screening. ${ }^{9}$ Screening is done through cytologybased screening (Pap test), HPV based screening, visual inspection of aceto-white cervix (VIA), colposcopic examination. ${ }^{10,11}$

According to the American Cancer Society (ACS), before 1980, a Pap smear was recommended as part of a regular check-up. From 1980 to 1987 , pap smears with cervical cytology were recommended yearly for women over the age 20. ${ }^{12}$ Liquid-based cytology (LBC) technique has been approved for the first time by American Food and Drug Administration (FDA) as a cervical screening test at 1996 and it permitted simultaneous HPV screening, but it is not available in developing country. ${ }^{13,14}$

In 2002 for the first time the American Cancer Society (ACS) guideline for the early detection of cervical cancer incorporated HPV DNA testing. ${ }^{15}$ In the 1980 s, HPV was found to be the most important causative agent for cervical cancer, with nearly $100 \%$ of cervical cancer cases testing positive for HPV. ${ }^{12}$

The IARC (International Agency for Research on Cancer) classified HPV genotypes into two groups; the high-risk types $16,18,31,33,35,39,45,51,52,56,58$ and 59 have been defined as class I carcinogens and type 68 as class II carcinogens, and the low risk types 6,11 , 42,43 and 44 which are associated with hyperplastic lesions such as genital warts. ${ }^{16}$

A variety of HPV DNA detection assays are currently considered clinically validated with cervical scraping for cervical cancer screening purposes: PCR, Digene Hybrid Capture 2 (HC2) and INNO-LiPA (Innogenetics-Line Probe Assay). ${ }^{17,18}$

\section{METHODS}

This study was designed as cross-sectional study. It was conducted on 100 women from those attending cervical screening clinic or gynecology clinic in Alexandria University Hospital. Aged 30-60 years, asymptomatic women seeking screening for cancer cervix. The research protocol was approved by the ethics committee of
Alexandria University. Informed consents were taken from all participants.

Participants were subjected to history taking, complete general examination, speculum examination, TVUS. Then Pap smear, cervical swab for HPV DNA testing were done at the same setting. After that, HPV DNA extraction, amplification and detection according to the manufacturer's instruction manual "Sansure Biotech Inc. Changsha, China", by applying real-time fluorescence quantitative PCR technology were done in Alexandria Regional Center for women health laboratory and Alexandria University Hospital Laboratory.

Follow up of cases according to Pap results and HPV DNA results. Cases with HSIL, positive HPV were subjected to visual inspection after application of 5\% acetic acid (VIA), colposcopy and colposcopic guided biopsy from founded lesions or acetowhite areas. Cases of LSIL or ASCUS were re-smeared after 3-6 months, if regression occurred nothing were done. If persistent or progressive intraepithelial lesion (LSIL or ASCUS) the cases were subjected to VIA, colposcopic examination and biopsy from suspected areas. Office punch directed biopsy was taken from the aceto-white epithelium. Biopsy sample was fixed immediately and submitted for histopathological examination.

Then statistical analysis of the data, data were fed to the computer and analyzed using IBM SPSS software package version 20.0. Comparison between different groups regarding categorical variables was tested using Chi-square test. When more than $20 \%$ of the cells have expected count less than 5, correction for chi-square was conducted using Fisher's Exact test or Monte Carlo correction. If the data were abnormally distributed, nonparametric tests were used for normally distributed data, comparison between the two studied groups were done using independent t-test while for abnormally distributed data, comparison were done using Mann Whitney test. Significance of the obtained results was judged at the 5\% level.

\section{RESULTS}

$21 \%$ of cases were HPV positive and $79 \%$ were HPV negative, $66 \%$ were positive for intraepithelial lesions (37\% ASCUS, 18\% LSIL, 11\% HSIL) and 34\% were negative for intraepithelial lesions (30\% normal, $1 \%$ inflammatory atypia, 3\% squamous metaplasia) (Figures 1 to 3$)$.

The relation between HPV DNA results and abnormal cytology results was demonstrated in (Table 1) and it showed that 66 cases had intraepithelial lesions of the cervix: 11 had HSIL from those 11 cases 3 were -ve for HPV and 8 were +ve for HPV, 18 cases had LSIL from those 18 cases 17 were -ve and 1 was +ve for HPV, 37 cases had ASCUS from them 31 were -ve and 6 were +ve 
for HPV) there was significant positive association between HSIL and HPV DNA positivity.

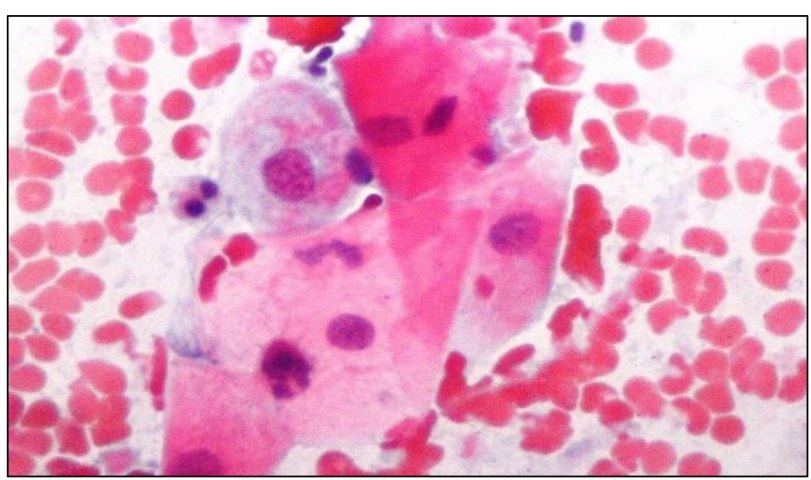

The cells resemble superficial or intermediate squamous cells in size and configuration, nuclei are round with minimal irregular outlines and size 2-3 times of normal intermediate cell or twice the squamous metaplastic cell.

Figure 1: Example of a case with Pap smear positive for intraepithelial lesion ASCUS ( $\times 400)$.

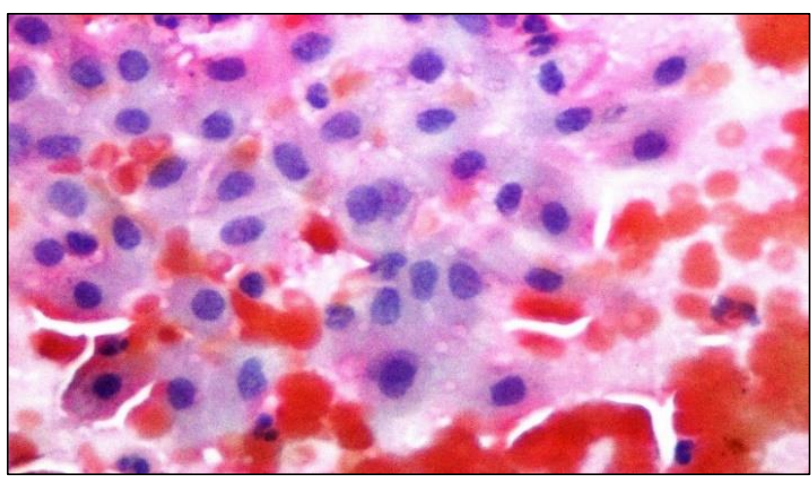

Note the large nuclei that are 4-6 times the size of a normal intermediate cell nuclei, nucleoli are absent. There is increased nucleo/cytoplasmic ratio and the cells are present single or in clusters.

Figure 2: Pap smear positive for intraepithelial lesion LSIL $(\times 200)$.

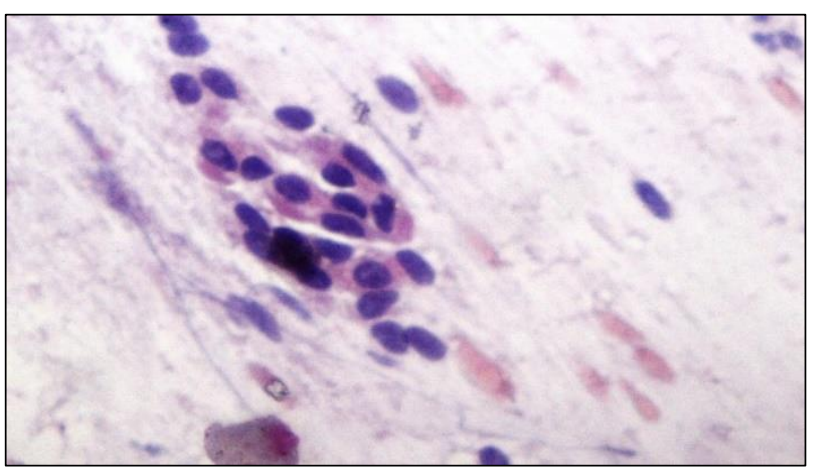

The cells are smaller show enlarged nuclei and reduced cytoplasm resulting in a marked increase in the nuclear/cytoplasm ratio and increased degree of nuclear atypia. The nuclei are more hyperchromatic and irregular than in LSIL.

Figure 3: Example of a case with Pap smear positive for intraepithelial lesion HSIL (x200).
Cases of ASCUS and LSIL were re-smeared after 3-6 months and there was regression of abnormality in 34 cases $(91.9 \%)$ and 13 cases $(72.2 \%)$ respectively. While there was persistence of abnormality in 3 cases $(8.1 \%)$ of ASCUS and 5 cases $(27.8 \%)$ of LSIL.

Colposcopic examination of cases with HSIL (10 out of 11 cases attended), positive HPV (16 out of 21 cases attended) and persistent ASCUS and LSIL. All cases with abnormal cytology examined by VIA test, colposcopy had abnormal lesions and biopsies were taken and 10 out of 16 cases HPV positive $(62.5 \%)$ had abnormal lesions by colposcopy and biopsies were taken and the results were 14 cases of CIN I and 4 cases of CIN II (Table 2), (Figures 4, 5).

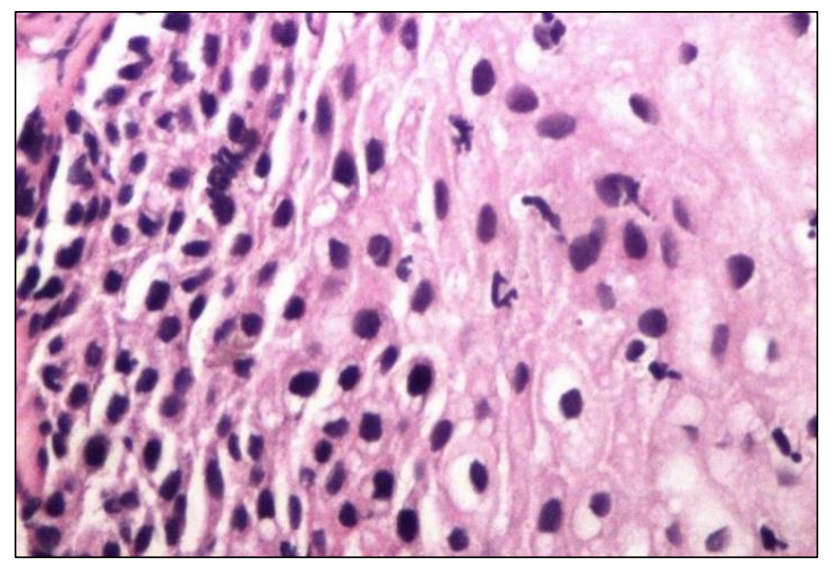

Cells are atypical basaloid cells occupying the lower two thirds of the cervical epithelium and koilocytosis is also found.

Figure 4: Cervical biopsy of a case of HSIL by Pap, showing moderate dysplasia (CIN II), H and E stain $(\times 400)$.

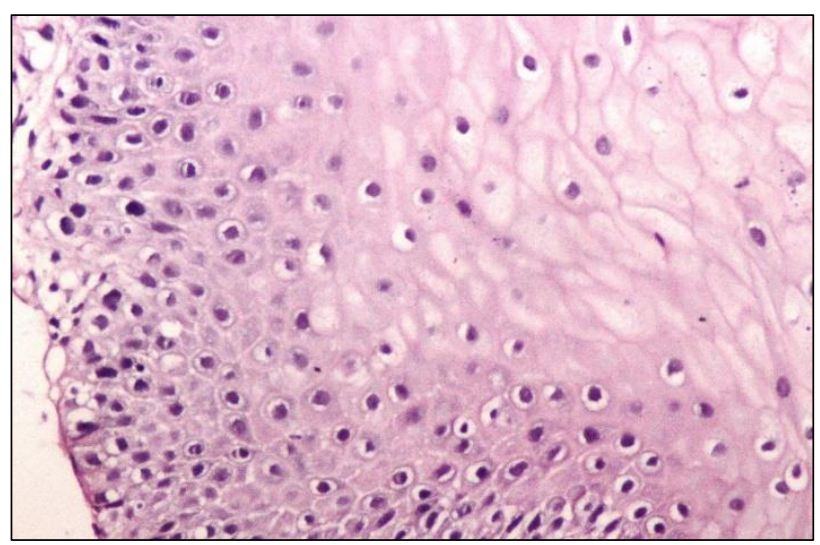

Atypical cells occupying the lower third of the cervical epithelium.

Figure 5: Cervical biopsy from a case of LSIL by Pap, showing mild dysplasia (CIN I), H and E stain $(\times 200)$.

Table 2 showed that 7 out of $10 \mathrm{HPV}+$ ve cases had CIN I and 3 cases had CIN II, 6 out of 10 cases with HSIL had CIN I and 4 cases had CIN II. 5 cases of LSIL and 3 cases of ASCUS had CIN I. 
Table 1: Relation between HPV DNA results and different types of abnormal cytology.

\begin{tabular}{|c|c|c|c|c|c|c|}
\hline & \multicolumn{6}{|c|}{ HPV } \\
\hline & \multicolumn{2}{|c|}{ Negative $(n=51)$} & \multicolumn{2}{|c|}{ Positive (n = 15) } & \multirow[t]{2}{*}{$\chi^{2}$} & \multirow[t]{2}{*}{ p } \\
\hline & No. & $\%$ & No. & $\%$ & & \\
\hline Positive smears & & & & & $16.229 *$ & MCp $<0.001 *$ \\
\hline Cases with HSIL & 3 & 5.9 & 8 & 53.3 & 18.791 & FEp $<0.001 *$ \\
\hline Cases with LSIL & 17 & 33.3 & 1 & 6.7 & $4.156^{*}$ & $\mathrm{FEp}=0.051^{*}$ \\
\hline Cases with ASCUS & 31 & 60.8 & 6 & 40.0 & 2.033 & 0.154 \\
\hline
\end{tabular}

$\chi^{2}, \mathrm{p}: \chi^{2}$ and $\mathrm{p}$ values for Chi square test for comparing between the two groups; MC: Monte Carlo for Chi square test; FE: Fisher Exact for Chi square test; *: Statistically significant at $\mathrm{p} \leq 0.05$

Table 2: Histopathological study of punch biopsies.

\begin{tabular}{|c|c|c|c|c|c|c|c|c|}
\hline \multirow[t]{2}{*}{ Biopsy for results of punch biopsy } & \multicolumn{2}{|c|}{$\begin{array}{l}\text { DNA positive cases } \\
(\mathrm{n}=10)\end{array}$} & \multicolumn{2}{|c|}{$\begin{array}{l}\text { HSIL cases } \\
\text { attended }(n=10)\end{array}$} & \multicolumn{2}{|c|}{$\begin{array}{l}\text { LSIL cases } \\
(\mathrm{n}=5)\end{array}$} & \multicolumn{2}{|c|}{$\begin{array}{l}\text { ASCUS cases } \\
(\mathrm{n}=\mathbf{3})\end{array}$} \\
\hline & No. & $\%$ & No. & $\%$ & No. & $\%$ & No. & $\%$ \\
\hline Mil & 7 & 70.0 & 6 & 60.0 & 5 & 100.0 & 3 & 100.0 \\
\hline Moderate dysplasis (CIN II) & 3 & 30.0 & 4 & 40.0 & 0 & 0.0 & 0 & 0.0 \\
\hline
\end{tabular}

Table 3: Relation between HPV 16, 18 DNA results and cytology results.

\begin{tabular}{|c|c|c|c|c|c|c|}
\hline & \multicolumn{4}{|c|}{ Cytology } & \multirow{3}{*}{$\mathrm{C}^{2}$} & \multirow{3}{*}{ p } \\
\hline & \multicolumn{2}{|c|}{ Normal $(n=34)$} & \multicolumn{2}{|c|}{ Abnormal (n = 66) } & & \\
\hline & No. & $\%$ & No. & $\%$ & & \\
\hline \multicolumn{7}{|l|}{ HPV } \\
\hline Negative $(\mathrm{n}=79)$ & 28 & 82.4 & 51 & 77.3 & \multirow{2}{*}{0.349} & \multirow{2}{*}{0.555} \\
\hline Positive $(\mathrm{n}=21)$ & 6 & 17.6 & 15 & 22.7 & & \\
\hline Sensitivity & 22.73 & & & & & \\
\hline Specificity & 82.35 & & & & & \\
\hline PPV & 71.43 & & & & & \\
\hline NPV & 35.44 & & & & & \\
\hline Accuracy & 43.00 & & & & & \\
\hline
\end{tabular}

According to the study results, HPV DNA testing had sensitivity $22.73 \%$, specificity which was $82.35 \%$, positive predictive value (PPV) $67.43 \%$, negative predictive value (NPV) $35.44 \%$ and accuracy $43.0 \%$ when compared with Pap test (Table 3).

\section{DISCUSSION}

Cervical cancer is associated with several risk factors including human papilloma virus infection, smoking, sexual behaviour and hormonal contraceptive consumption., 5 High quality cervical screening can contribute to a reduction in the incidence and mortality of cervical cancer. ${ }^{19}$ The results of this study suggests that HPV 16, 18 DNA test is less sensitive than Pap smear in early detection of pre-invasive disease of the cervix, and the cytology is primary to HPV DNA as a screening method.

In agreement with the present study, Syrjänen et al, in a study of 3175 women for screening of cancer cervix using routine cytology and HPV testing, found that Pap smear cytology detected high-grade lesions with a sensitivity of $64.0 \%$, specificity of $89.1 \%$, while $33.0 \%$ of cases were positive for oncogenic HPV types. ${ }^{20}$ On the contrary, Castle et al, in a study of 797,927 women, Pap smears and HPV DNA testing for 13 carcinogenic HPV genotypes were performed. ${ }^{21}$ The study concluded that the likelihood of testing carcinogenic HPV positive but cytologic negative to be only slightly more common than the likelihood of testing carcinogenic HPV negative but cytologic positive (3.99\% versus $2.90 \%)$.

Carozzi et al, in a study stated that HPV test detected 99.2\% (132 out of 133) of CIN2 cases diagnosed during the follow-up period, with a median follow-up time of 1.6 years. ${ }^{22}$ The risk of CIN2 within 5 years with a negative HPV test was $0.44 \%$ in the follow up period. According to the present study results, there was statistically significant relationship between HSIL and HPV positivity as $72.73 \%$ ( 8 cases) of cases with HSIL were HPV positive. In agreement with our study, Allameh et al, studied 130 cases with abnormal cytology by doing HPV DNA test. ${ }^{23}$ The results of this research indicated that the prevalence of HPV infection is high in all categories of cervical neoplasia especially in precancerous lesions. Jung An et al, in a study including 1983 women, concluded that $98.1 \%$ of HSILs, were HPV positive, and 
found that HPV-16 was the most prevalent type in HSILs $(51.9 \%)$, followed by HPV-58 (15.7\%) and HPV-18 $(6.7 \%){ }^{24}$

\section{CONCLUSION}

HPV-DNA positivity has positive association with HSIL. Pap smear is an easy cheap method for screening. HPVDNA test is less sensitive than cytology as a method for screening.

\section{ACKNOWLEDGMENTS}

Authors would like to thank all participants in this study for their effort. Authors would like to thank Alexandria Regional Center and Prof. Sameh Saad Eldin Sadek for help in the financial support of the research and their laboratory staff for help in preparation of cervical swabs for HPV DNA investigation. Authors would also like to thank all women who participated in the research and Alexandria University Gynecologic clinic staff for their help.

Funding: Alexandria Regional Center for Women Health Conflict of interest: None declared

Ethical approval: The study was approved by the Institutional Ethics Committee

\section{REFERENCES}

1. Ali-Risasi C, Verdonck K, Padalko E, Vanden Broeck D, Praet M. Prevalence and risk factors for cancer of the uterine cervix among women living in Kinshasa, the Democratic Republic of the Congo: a cross-sectional study. Infect Agent Cancer. 2015;10:20.

2. Bermudez A, Bhatla N, Leung E. Cancer of the cervix uteri. Int J Gynaecol Obstet. 2015;131:88-95.

3. Abudukadeer A, Azam S, Mutailipu AZ, Qun L, Guilin G, Mijiti S. Knowledge and attitude of Uyghur women in Xinjiang province of China related to the prevention and early detection of cervical cancer. World J Surg Oncol. 2015;13:110:17.

4. Ibrahim AS, Khaled HM, Mikhail NNH, Baraka H, Kamel H. Cancer Incidence in Egypt: results of the national population-based cancer registry program. J Cancer Epidemiol. 2014:1-18.

5. Danaei G, Hoorn VS, Lopez AD, Murray CJ, Ezzati M. Causes of cancer in the world: comparative risk assessment of nine behavioral and environmental risk factors. Lancet. 2005;366(9499):1784-93.

6. Manga MM, Fowotade A, Abdullahi YM, El-Nafaty AU, Adamu DB, Pindiga HU, et al. Epidemiological patterns of cervical human papillomavirus infection among women presenting for cervical cancer screening in North-Eastern Nigeria. Infect Agent Cancer. 2015;10:39.

7. Bueno CT, da Silva DCM, Barcellos RB, da Silva J, Dos Santos CR, Menezes JE, et al. Association between cervical lesion grade and micronucleus frequency in the Papanicolaou test. Genet Mol Biol. 2014;37(3):496-9.

8. Anttila A, Ronco G, Clifford G, Bray F, Hakama M, Arbyn M, et al. Cervical cancer screening programmes and policies in 18 European countries. Br J Cancer. 2004;91:935-41.

9. Smith RA, Manassaram-Baptiste D, Brooks D, Cokkinides V, Doroshenk M, Saslow D, et al. Cancer screening in the United States, 2014: a review of current American Cancer Society guidelines and current issues in cancer screening. CA Cancer J Clin. 2014;64(1):30-51.

10. Orang'o EO, Wachira J, Asirwa FC. Factors associated with uptake of visual inspection with acetic acid (VIA) for cervical cancer screening in Western Kenya. PloS On. 2016;11(6):1-12.

11. Jin XW, Lipold L, Foucher J. Cost-effectiveness of primary hpv testing, cytology and co-testing as cervical cancer screening for women above age 30 years. Gen Intern Med. 2016:1-7.

12. Davis M, Feldman S. Making Sense of cervical cancer screening guidelines and recommendations. Curr Treat Options Oncol. 2015;16(12):55.

13. Lee KR, Ashfaq R, Birdsong GG, Corkill ME, McIntosh KM, Inhorn SL. Comparison of conventional Papanicolaou smears and a fluid-based, thin-layer system for cervical cancer screening. Obstet Gynecol. 1997;90(2):278-84.

14. Ring $\mathrm{M}$, Bolger $\mathrm{N}$, O'Donnell $\mathrm{M}$, Malkin A, Bermingham N, Akpan E, et al. Evaluation of liquidbased cytology in cervical screening of high-risk populations: a split study of colposcopy and genitourinary medicine populations. Cytopathol. 2002;13:152-9.

15. Saslow D, Solomon D, Lawson HW. American society for colposcopy and cervical pathology, and American Society for clinical pathology screening guidelines for the prevention and early detection of cervical cancer. Ca Cancer J Clin. 2012;62:147-72.

16. Boehmer G, Wang L, Iftner A, Holz B, Haedicke J, von Wasielewski $\mathrm{R}$, et al. A population-based observational study comparing Cervista and Hybrid Capture 2 methods: improved relative specificity of the Cervista assay by increasing its cut-off. BMC Infect Dis. 2014;14:674.

17. Hesselink AT, Berkhof J, van der Salm ML. Clinical validation of the HPV-Risk assay, a novel real-time pcr assay for detection of high-risk human papillomavirus dna by targeting the e 7 region. J Clin Microbiol. 2014;52:890-6.

18. Ngou J, Gilham C, Omar T, Goumbri-Lompo O, Doutre S, Michelow $\mathrm{P}$, et al. Comparison of analytical and clinical performances of the digene HC2 HPV DNA assay and the inno-lipa hpv genotyping assay for detecting high-risk hpv infection and cervical neoplasia among HIV-positive African Women. JAIDS. 2015;68(2):162-8. 
19. Klinkhamer JP, Meerding WJ, Rosier PF. Liquid Based Cytology. Cancer Cytopathol. 2003;99:26371.

20. Syrjänen S, Shabalova IP, Petrovichev N, Kozachenko VP, Zakharova T, Pajanidi J, et al. Human papillomavirus testing and conventional pap smear cytology as optional screening tools of women at different risks for cervical cancer in the countries of the former Soviet Union. J Low Genit Tract Dis. 2002;6:97-110.

21. Castle PE, Fetterman B, Poitras N, Lorey T. FiveYear experience of human papillomavirus DNA and Papanicolaou test cotesting. Obstet Gynecol. 2009;113(3):595-600.

22. Carozzi F, Visioli CB, Confortini M, Iossa A, Mantellini P, Burroni E, et al. hr-HPV testing in the follow-up of women with cytological abnormalities and negative colposcopy. $\mathrm{Br} \mathrm{J}$ Cancer. 2013;109(7):1766-74.
23. Allameh T, Moghim S, Asadi-Zeidabadi M. A survey on the prevalence of high-risk subtypes of human papilloma virus among women with cervical neoplasia in Isfahan University of Medical Science. Arch Gynecol Obstet. 2011;284(6):1509-13.

24. An HJ, Cho NH, Lee SY, Kim IH, Lee C, Kim SJ, et al. Correlation of cervical carcinoma and precancerous lesions with human papillomavirus (HPV) genotypes detected with the HPV DNA chip microarray method. Cancer. 2003;97(7):1672-80.

Cite this article as: Nwesar FA, Salam TAT, Hanafi MM, Younis LK, Abou-Zeid ZS, Elkaffash DMN. The use of HPV-DNA testing combined with Pap smear in detection of pre-invasive disease of the cervix. Int J Reprod Contracept Obstet Gynecol 2017;6:5192-7. 